\title{
Perceptions of Antenatal Women, Husband and Health Service Providers on Husband being Birth Companion during Childbirth: A Qualitative Study
}

\author{
Kaveri $\mathrm{M}^{1}$ and Kumar AIK ${ }^{2 *}$ \\ ${ }^{1}$ Oxford Policy Management, India \\ ${ }^{2}$ School of Public Health, SRM University, India
}

*Corresponding author: Anil Kumar Indira Krishnan, School of Public Health, SRM University, India, Tel: 9345303063; E-mail: ikanilkrishna@gmail.com

\section{Research Article}

Volume 1 Issue 1

Received Date: January 10, 2017

Published Date: January 20, 2017

\section{Abstract}

Objectives: 1) To explore the perceptions of pregnant woman, husband and service providers about the presence of husband as a birth companion during childbirth. 2) To know the birth experiences of women who are multiple gravid.

Data Sources: Primary data is collected from two selected hospitals in Kolkata, one each of a private and government hospital. Methodology: An exploratory study design is adopted to elicit information from the selected respondents. In-depth interviews are conducted with 38 pregnant women and 38 husbands, who were beneficiaries of the selected hospitals. Besides this, 24 health service providers were interviewed who were working in one of the two selected hospitals. The checklist was used for gathering information which was pre tested.

Findings: Most respondents perceived the practice of allowing husband as a birth companion will be an advantage for reasons like moral support, inner strength and confidence for woman in labor and lesser fear of pain for her. They also felt it will ensure respectful behavior from service providers. Some respondents perceived this practice can reduce domestic violence, and increase usage of spacing and limiting methods of family planning too. Respondents also believed it will compromise with the privacy of other women who will be delivering in the same room and would bring stigma from the cultural point of view. Service providers have this opinion and have also shared their experience that husbands generally become sick and giddy as they are not used to be in such a situation.

Conclusion: Women generally perceived that having their husbands as birth companion would significantly improve the quality of their birthing experience. The providers also seemed to share this view, though some felt that having husband might have negative consequences.

Keywords: Antenatal Women; Birth Companion; Childbirth; Husband; Health care providers; Perceptions

\section{Introduction}

Birth companion is a person whom a woman chooses to be with her when she is giving birth to a baby (Oxford - 
Advance Learners Dictionary). Birth companion is referred to as birth partner or labor support as well. In many countries like Australia, USA and Sweden, husband is allowed during childbirth to provide support during labor and they also undergo prior classes \& counseling during Antenatal Period. In India, barring a few exceptions it is neither practiced much nor is studied indepth.

\section{Literature Review}

Many small and large scale studies have been conducted in different parts of world that have confirmed that birth companion is a process which carries benefits not only for women, but also for their husband and newborn. Studies have proven that having husband as a birth companion: Provides comfort and support for the mother.

- Husband can ensure that the wife's preferences are followed, and can ensure any important Reduces fear and anxiety, increases concentration on breathing techniques, increase self-confidence and decrease emotional stress during labor.

- It helps father to bond with the child.

- Woman is likely to take lesser analgesics.

- Decision can be taken carefully in case an emergency occurs.

- Enables the wife to cope with labor in more beneficial ways, like breathing in-stead of screaming.

- Supported women report slightly shorter labors.

- More chances of a spontaneous vaginal delivery.

Several western studies have shown that having the husband as the birth companion has significant positive effects such as reduced duration or labor, reduced pain perception, and an overall positive feeling.

A comparative study conducted by Rosemary and William in US (1975) [compared groups with and without birth companion. But husbands were enrolled in childbirth education classes beforehand. The study showed women reported lesser pain, took lesser medication and showed more positive feeling about the total birthing experience [1].

A study by Britta in Nepal (2005) considered a little larger perspective and aimed to understand the barriers towards male involvement in maternal health which includes childbirth experience, and also explores men, women and providers attitude towards promotion of male involvement. It found job responsibility, shyness, embarrassment, social stigma and low knowledge levels as major reasons from men. The providers listed some other obstacles like hospital policy, small space in labor room and less manpower. Providers also felt that this will help in provision of better quality of maternal care and enhance understanding of the health information given to antenatal woman. Both men and women showed positive attitudes towards male involvement in maternal health [2].

A large scale review of studies was conducted by the Cochrane Collaboration having Hodnett, Gates, Hofmeyer and Sakala as main investigators (2007). The review of studies includes 16 trials from 11 countries involving 13391 women in a wide range of settings and circumstances. The findings showed that women who got continuous support were more likely to undergo spontaneous vaginal delivery. Alongside they were more likely to use lesser analgesics, more likely to be satisfied and had slightly shorter labor. No adverse effects were identified in the process of allowing a birth companion and the whole process appeared to be more effective when commenced early in labor. The authors concluded saying that all women should have continuous support during labor and childbirth [3].

Heather et al. conducted a randomized study on promoting childbirth companions in South Africa. This study also brought attention on the labor room experiences of women. Results show one third of women being given episiotomy. $17.7 \%(\mathrm{~N}=2085)$ women were shouted at, a few (4.3\%) reported of being struck or slapped. Majority of hospitals did not allow birth companions. The researchers concluded that introduction of birth companion was found more difficult than anticipated. The quality and humanity of care needs improvement [4].

In another study in South Africa, Jean (1999) looked at the effects of having a birth companion in labor, mostly its association with postnatal depression. On assessment after 6 weeks of childbirth, those who had birth companion and had support all through the six weeks, showed higher self esteem, lower anxiety and lower depression than that of the control group who were not attended by birth companions. Not a single supported woman became highly depressed, whereas among those not supported 22\% showed high depression scores [5].

Ahmed et al. conducted a cross-sectional study to know the parturient need of continuous labor support in labor wards. The study results say that $54 \%$ and $37 \%$ of women want their mother and husband respectively as their birth 
companion. The reasons of wanting this support were many, like emotional (49.5\%), information (25\%) and physical support (21.7\%) [6].

A study by Morhasson et al. found Nigerian antenatal women desire their spouse to support them during childbirth. The study also confirmed that psycho-social support has been shown to be associated with better delivery outcomes like reduced $\mathrm{C}$-section rates, shorter labor duration and earlier initiation of breast feeding [7].

In this study we make a sincere effort to understand the perception of antenatal women, husbands and health service providers about the husband being allowed to be the birth companion.

\section{Objectives}

The objectives of this study were to explore the perception of pregnant woman, husband and service providers about the presence of husband as a birth companion during childbirth and to know the birth experiences of multi-gravid women.

\section{Methods}

The primary stakeholders of this study are pregnant women, husbands and health service providers. A Government and a Private hospital in Kolkata were selected data collection. Both the hospitals are specialized in Gynecology and Obstetrics. Permission is taken from the Medical Superintendent of the hospitals. Informed verbal consent was taken before interviewing the respondents. Following are the inclusion criteria for the respondents:

1. Any married pregnant woman who is a beneficiary of any of the two study hospitals.

2. Any married man, whose wife is pregnant and is a beneficiary of any of the two study hospitals.

3. Doctors, Nurses and Administrators who are working in the government or private hospital selected.

In-depth interviews were conducted with pregnant women, husbands and service providers to collect data qualitatively. Table 1 show the sample covered.

Kaveri M and Kumar AIK. Perceptions of Antenatal Women, Husband and Health Service Providers on Husband being Birth Companion during Childbirth: A Qualitative Study. Public H Open Acc 2017, 1(1): 000101.

\begin{tabular}{|c|c|c|c|}
\hline \multirow{2}{*}{$\begin{array}{c}\text { S } \\
\text { No. }\end{array}$} & \multirow{2}{*}{ Target Group } & \multicolumn{2}{|c|}{ Sample covered } \\
\cline { 3 - 4 } & $\begin{array}{c}\text { Govt. } \\
\text { Hospital }\end{array}$ & $\begin{array}{c}\text { Private } \\
\text { Hospital }\end{array}$ \\
\hline 1 & Pregnant women & 36 & 2 \\
\hline 2 & Husband & 36 & 2 \\
\hline 3 & \multicolumn{2}{|c|}{ Service providers } \\
\hline 3.1 & Doctors & 4 & 4 \\
\hline 3.2 & Nurses & 7 & 4 \\
\hline 3.3 & Administrators & 2 & 2 \\
\hline 3.4 & Counselor & 1 & 0 \\
\hline
\end{tabular}

Table 1: Sample Covered.

Three different tools were prepared for three types of respondents. These tools were pretested at SRM Hospital, Kattankulathur. Sequence of some questions was changed on the basis of interviews conducted. Final data collection for the study was done in June 2011, over a period of 3 weeks in Kolkata.

\section{Findings: Perception on Birth Companion}

Perception on Birth Companion: The concept of birth companion was very new to pregnant women and husbands, although service providers had heard about it. Service providers were interviewed from two hospitals. The Government hospital that was selected did not allow birth companion. The private hospital selected for the study was allowing husbands as birth companion since last 11 years.

\section{Privacy}

Pregnant women: Privacy played dual role. Women perceived that their privacy will ensure their privacy is maintained in delivery room but some have this opinion that in a government hospital set up, where more than one woman deliver in the same room, the privacy of other women will get compromised if husband is allowed. "There will be other women too delivering in the same room; it will be very uncomfortable for them." A primigravid woman said.

Husband: Privacy of other women was a very common reason among men as well who did not want to be birth companion. One of them said, "I will ask my mother or sister to stay if allowed. Since many women will be delivering there, their privacy is at stake." 
Health Service providers: Although service providers perceived it as a good practice but they also discussed its pros and cons. A nursing personnel from the government hospital said, "We are having three labor tables side by side. It's difficult to allow the husbands here without any privacy. This can happen at private hospitals where separate cabins are allotted to every client but in our setting it's not possible."

\section{Fear}

Pregnant Women: Women shared that there is a certain amount of fear attached to hospitals inclusive of the fear of unknown. Some very bitter experiences were found out in the interview of multi gravid women, related to the behavior of service providers. One of the women shares her experience of a previous cesarean section in a Government hospital.

"Last time the hospital where we went, the attitude of doctors was completely indifferent. They dint show any concern. They did not check BP every time I went there. Even if they checked weight they didn't tell me. I think if my husband is there the doctors will behave properly. Last time I remember after I came to consciousness after my surgery I asked for some water and lifted my head but the doctor pulled me by my hair to make me lie down. I felt very bad and told my husband so we decided to get treated at some other hospital."

Another respondent said she was not satisfied with the care she received at the hospital she delivered last time. She says, "I was in labor and I was screaming out of pain, then one of the doctors said you did not think twice when you so comfortably had sex and now you are screaming? You did not realize that you will have to undergo this much pain?"

Husband: Husbands demonstrated understanding towards the pain and suffering during childbirth. A statement made by one of them, "If that helps my wife in any way I'll stay." clearly shows the understanding. One of them said, "There won't be chances of switching the baby if I am there." On the other hand one of them said; "I am scared to see blood and can't stand its smell."

The fear of ill treatment from the service providers came from the experience of a respondent, "I have got the blow once I won't let it happen again. The doctors said if the Hepatitis $B$ vaccine was given in the cord after delivery the child could be saved. But they did not do that even after knowing my wife medical status and my child died."

Service Providers: A nursing personnel said, "Suppose the husband is waiting outside and hears his wife screaming, he will not know what happened inside the labor room and might think we are beating her. But if he is inside he will see everything in front of him and that she screamed out of pain and wont blame us." A similar statement was made by another staff nurse, "Many a times it had happened that the mother is confused during delivery and cannot identify the gender of the baby and reports incorrectly later, the husband shall be helpful in such situations. If husband is allowed inside then we get a chance to be transparent."

\section{Help and support during pregnancy}

Pregnant Women: "I will be motivated to bear the pain." was a very common statement. A primi gravid woman said, "He will take care of me and I'll feel that he is sharing my pain and suffering." Women commonly felt that their husband being beside them will be greatest support. "Husband will be the best birth companion as there are things we don't even share with our mother. Mother is beloved for sure but I will be more comfortable in company of my husband during delivery." one of them adds.

Most women found it normal for husband to accompany his wife to diagnostic centre and antenatal clinic, but one of them says, "Shall he move with me everywhere I go like my tail? Husband should have better things to do...." She further added that she does not want her husband to be a birth companion, "..there is no need for him to be there in that position. Let him go where-ever he wants to go. I don't need him. My mother is there to be with me."

Some women got every possible help from their husband during antenatal days " he does not let me lift heavy weight, does not let me do anything and takes care of all household chores. He tells me this is your time to take complete rest" a pregnant woman added with a smile. Most of the women interviewed reported that their husband were supportive. Women commonly reported that they received help in household chores in the form of carrying water to bathroom, cooking, making bed in the morning and drying clothes. Some rare responses included washing clothes, utensils and sweeping the floor. Among women who did not receive any help from their husband, there were some who were staying in a joint family and received help from mother in law or sister in law. One of the women looked shocked when the question 
was asked, she said, "He helps me financially and that is enough."

Husband: Husbands said that they wanted to provide mental strength and confidence to the woman to bear pain and stay strong. One of them said, "My wife will get more courage and strength to bear the pain."

Among the husbands who reported that they help their wife during pregnancy, some very common responses were cooking, bringing water, cutting vegetables and lifting anything heavy. Some rare responses like sweeping, washing clothes were also given. A respondent said, "I tell her to do things on her own. But if anything is left undone I will come home and try to do it. But I encourage her to do as much as possible."

Service Providers: A service provider reports having prior interest in this practice and has read a lot about it. She said, "Husband will be able to feel what a wife undergoes to deliver a baby. Secondly it helps to reduce the intensity of pain. Then this will work in an active way in spacing as the husband will see it is this painful and he might consider spacing or limiting methods of family planning. Then the joy of childbirth will be shared by both the parents. In any problem he will be able to identify and act as a support person. In case an emergency arises he will be helpful in taking important decision."

Respondents believed that it works a big way by increasing the understanding between the couple and women might get more support from their husband in future. A doctor from the government hospital says, "Husband will see how much pain a woman undergoes he might consider spacing or limiting methods of family planning. He might not go to other women in future and be loyal to his wife."

A nursing personnel from the same hospital adds, "The woman in labor will get mental support and will feel more encouraged to go through the pain and the joy of childbirth will be shared by both the parents." They also perceived that the couple will be more satisfied with the process of childbirth if birth companion is allowed. Another doctor says, "Husband will be able to convince his wife in difficult situations and also in case of emergency arises he will be able to take necessary decisions understanding the situation." He enthusiastically added, "Mother will be more relaxed and in a better condition and will have more steady recovery. The baby will be able to see both parents from the beginning." Another doctor says, "There might be lesser domestic violence after the husband witnesses the amount of pain their wife bear to give birth to their child."

\section{Culture}

Pregnant women: "After delivery people in the society will pass comments that he stayed with me in that situation. I don't want to hear that." added by a 17 year old respondent, who came for ante-natal check up at the government hospital.

Husband: Not wanting or wanting to be a birth companion is also guided by societal and cultural norms, family pressure and bitter experiences in the past. A respondent said, "My family will mind. Our cultural values and principles do not allow that. I don't think men should stay in that position."

\section{Learning opportunity}

Pregnant women: One of the pregnant women said, "It will be a great experience for the father." They believed that husbands have always been outside the room in this situation and they do not understand how much pain a woman bears during delivery. " They have a very rosy picture painted in front of their eyes as they see a screaming woman going inside and a nurse bringing the cleanly wrapped baby to show." Another woman says.

Husband: Some of the husbands also said that they are never allowed inside the labor room. They are curious to know what happens inside and that they will learn a lot given an opportunity to be a birth companion, "... I will get knowledge about delivery as I have never been inside.."

Service providers: Some service providers did mention that it will be a great learning opportunity for husbands and it is important for them to this part of their lives.

\section{Management}

Health Service Provider: One of the doctors to says, "It's difficult to practice this keeping in mind the present manpower and then looking at the population of our country.".

Sister in-charge of a labor room says, "We will be able to manage labor properly as there will be better patient cooperation." A doctor from government hospital adds, "The misconception about the mismanagement will go away from the minds of clients and their family members." 
When asked whether they encourage husbands to accompany during antenatal visits, service providers reported that they encouraged family members to come. One of them says, "In our hospital we have special parenting classes for the parent to be." Another respondent from government hospital said, "It's important that the husbands accompany their wife as sometimes it affects more when they hear it coming straight from the horse's mouth. Mothers are dying in our country owing to anemia. People might feed them better when they hear it from us."

As the private hospital selected was already allowing Birth companion selectively, the responses of service providers came from their experience. The pros and cons that they listed came straight from their experience and practice. While telling the disadvantages one of them says, "When dealing with preterm baby and other complicated cases it's always better to keep the husband outside. It avoids them from getting anxious. I dislike the habit of video recording the delivery which husbands often do. What is so good about recording your wife when she is screaming with pain? We don't usually allow it but they insist."

\section{Discussion}

The perception of pregnant women was largely based on the love and support they received from their husband. When a woman found their husband supportive during pregnancy they expected them to be a birth companion and vice versa.

Some very striking findings have come out which are not mentioned in any of the literature reviewed. Service providers perceived this practice could reduce domestic violence. Also at places where it was already practiced, maintaining privacy of the clients was surely not an issue but in the government hospital taken in the study, it is definitely a concern. Some respondents also said there are issues with the behavior of service providers which acted as a motivating factor for the pregnant women and their husbands to want to have birth companion. Hopefully the presence of the birth companion would deter the ill treatment they felt. The service providers wanted to allow birth companion to keep the whole process transparent.

Health service providers generally accepted that allowing husband as a birth companion was a good practice. Almost all of them interviewed from the government hospital agreed it's difficult to take place due to managerial issues like challenging doctor patient and nurse patient ratio.
Managerial lacunae like lack of material, manpower and time were important findings. The private hospital was practicing this for 11 years but practices are not shared between hospitals. It was great finding the private hospital was already allowing the birth companion for so long. It was also found that this hospital conducts special parenting classes for the parents to be.

Husbands are encouraged to accompany to the antenatal visits but in the government hospital he is not allowed inside the doctor's chamber during advice and examination due to privacy issues. This was not an issue at the private hospital; in fact they also allowed husbands during USG.

Birth companion is also being seen as an opportunity to reinforce and encourage contraception, which again is an important finding. It may influence couple's to consider spacing and limiting methods of family planning. They also connected it to maternal mortality as there are chances of reduction in anemia with increase involvement of husbands in maternal care and thus reduction in maternal mortality.

There is a need to study the perceptions of women quantitatively also and understand what proportion of women want their husbands as birth companions and what proportion don't. The attitudes of providers should also be documented in future studies quantitatively. With the increasing focus on improving maternal health and improving the maternal health delivery services, this topic gains importance.

\section{References}

1. William HJ, Rosemary C (1975) The effect of husband participation on reported pain and probability of medication during labor and birth. J Psychosom Res 19(3): 215-22.

2. Mullany BC, Hindin MJ, Becker S (2005) Can women's autonomy impede male involvement in pregnancy health in Katmandu, Nepal? Soc Sci Med 6(9): 19932006.

3. Hodnett ED (2007) Continous support for women during childbirth (Review). John Wiley and sons Ltd.

4. Heather B, Justus H, Cheryl NV, Helen S, Paul G (2007) Promoting childbirth companions in South Africa-a randomized pilot study. BMC Med 30(5):7. 
5. Jean R (1999) Birth companion and post natal depression. AIMS Journal 11(1).

6. Ahmed A, Solomon K, Million T (2007) Parturients need for continuous labor support in labor wards. Ethiop J Health Dev 21(1): 35-39.

7. Oladosu OA, Imran BM, Babatunde A, Gbolahan O, Ami T. Husband support during childbirth as a catalyst for modern Family Planning uptake in Nigeria- a Randomized Control Trial.

8. Sample Registration System. Special Bulletin on Maternal Mortality in India 2007-2009, June 2011.

9. Sample Registration System (2011) SRS Bulletin.
10. Ip WY (2000) Chinese husband's presence during labor: a preliminary study in Hong Kong. Int J Nurs Pract 6(2): 89-96.

11. Scott KD, Klaus PH, Klaus MH (1999) The obstetrical and post partum benefits of continuous support during childbirth. J Women Health Gen-B 8(10): 1257-1264.

12. Census of India (2011) Provisional Population Totals. India series 1.

13. Kyle J (1992) Medical studies confirm benefits of labor support. Association of Labor Assistants and childbirth educators. 